\title{
Téoros
}

Revue de recherche en tourisme

\section{À la conquête de l'Arctique, la prochaine destination touristique}

\section{Jan Lundgren}

Volume 18, numéro 2, été 1999

La nordicité

URI : https://id.erudit.org/iderudit/1072003ar

DOI : https://doi.org/10.7202/1072003ar

Aller au sommaire du numéro

Éditeur(s)

Université du Québec à Montréal

ISSN

0712-8657 (imprimé)

1923-2705 (numérique)

Découvrir la revue

Citer ce document

Lundgren, J. (1999). À la conquête de l'Arctique, la prochaine destination

touristique. Téoros, 18(2), 3-3. https://doi.org/10.7202/1072003ar d'utilisation que vous pouvez consulter en ligne.

https://apropos.erudit.org/fr/usagers/politique-dutilisation/ 


\section{À la conquête de l'Arctique, LA PROCHAINE DESTINATION TOURISTIQUE}

\section{Jan Lundgren, rédacteur invité}

Lors de mon séjourd'un an à l'Université Mid Sweden, j'ai trouve par hasard un live qui venait d'être publié par le Département des etudes touristiques du Campus de la Cité d'Ostersund. Le titre étail plutor evocateur: The Journey to the Truly Unique Country - Le Pays Unique (en suédois "Resan till Landet 'Annorlunda $\%$ ). Le livre était publie sous la direction du professeur Bengt Sahlberg, aurrefois directeur des recherches au Sweden Tourism Board. Empreint de mes presque trente ans de vie au Canada, je cherchais un chapitre sur des destinations touristiques vraiment exclusives auxquelles mon expérience en territoire canadien pouvait se référer : la ruée vers l'or au Yukon, la conquête des rivières sawvages, les chutes du Niagara, les stations historiques de baleines « plus loin dans les eaux arctiques ., etc. Mais le livre ne consacrait aucun chapitre à ces sujets bien qu'on y trouvait, bien sar, d'autres articles fort intéressants à lire.

Un voyage dans le * Pays unique ", dans I'Inconnu, voilà une façon habile de décrire cé numéro de Téoros qui met en evidence le developpement du tourisme et des voyages aux confins du nond canadien et l'essor du tourisme dans l'Arctique et le Nord canadien depuis plas récemment. Ces ressources en sols d'une étendue telle qu'ils englobent le Nord et l'Artique, ainsi que leur caractère nordique, en font assurément des richesses touristiques nationales toutes particulières que peud'autres pays du Nord pewent se targuer de posséder, le Groenland étant peut-être la seule exception comme en fait foi un des articles de ce cahier.
Tout de même, le territoire de l'Arctique el du Nord canadien est exceptionnel, tant par ses dimensions gégraphiques que par sa faible densité de population, une équation qui ne se retrouve guère ailleurs sur la planète el qui en fait une destination touristique unique ! C'est d'ailleurs pourquoi ce territoine mérite la place que lui réserve un des numéros des séries régionales qui sont devenues au fil des ans une sorte de tradition de Téoros. J'espère que vous, chers lecteurs, chères lectrices, saurez en profiter.

Pour l'élaboration de ce numéro, Téoros a fail appel à la contribution d'auteurs aux acquis plutôt diversifiés, mais ayant tous et toutes un intérét particulier pour le domaine des études touristiques. Par exemple, François Bédand et Hélèe Huand abordent le sujet du tourisme industriel. version moderne et nordique, par le biais d'une analyse sur la croissance du tourisme dans la région de la Baie-James, une region qui, avant le projet d'aménagement hydro-électrique était bien peu accessible. Lowis-Edmond Hamelin et Luc-Normand Tellier traitent de plusieurs aspects du concept centre/périphérie appliqué à la zone froide, mais dans des contextes différents : l'application de la notion de nordicité selon Hamelin versus le paradigme plus général de centre/périphérie de Tellier. Quan à Jan Lundgren, il fonde son argumen principal sur l'imporiance de l'accessibilité aux destinations towristiques, un facteur qui a été le principal obstacle du développement touristique du Nord canadien en général. John C. Lehr. H. John Selwood et John S. Hull examinent les perspectives de développement du tourisme nondique des Prairies et de la côte du Labrador, ces deux régions ayant multiplié leurs efforts pour favoriser l'acces- sibilité aux régions eloignées, dans la région de la baie d'Hudson dans le cas du Nord du Manitoba et plus au nond, le long de la magnifique ligne côtière du Labrador: Quant à Maryse Grandbois, elle propose une analyse des approches formulees par Parcs Canada en matière d"elaboration de politiques et de planification des ressources, de la matrice de planification de developpement macro-géographique et de I'utilisation plus particulière des pratiques de planification environnementale des parcs conformément à la spécificité de chacun, en utilisant le Parc marin du Saguenay comme sujet d'analyse. Al Haller, un Inuk d'adoption depuis ses travawx de doctorat sur la côte Est de l'Arctique live une réflexion sur les impressions uniques que laisse l'environnement du Nord et de l'Arcrique sur le visiteur. Finalement, un compte rendu sur la présentation de Marianne Lykke Thomsen an Sommet mondial de la nordicité tenu a Québec en février dernier rappelle que l'Arctique et le Nord canadien ne constituent pas le seul Nord qui soit. Son voisin. le Groenland, semble être devenu * un géant touristique qui ne dort pas si profondément puisqu'il témoigne de ce qui peut être fait sur le plan touristique. De quoi songer. J'espere que vous apprécierez le contenu. Et la prochaine fois, partez à la decouverte du Nord!

Jan Lundgren est professeur retraité du Département de géographie de l'Université McGill. Specialisé en geographie du tourisme, son enseignement et ses recherches ont porté sur des régions aussi variées que les Caraübes, le Canada et la Scandinavié. Il est présentement professeur invité à I'Université Sorland à visby. Suede.

GE TEXTE A ÉTE TRADUIT DE L'ANGLAIS PAR MANON DUBUC. 